\title{
Telogen Effluvium Tanılı Hastaların Geriye Dönük Değerlendirilmesi
}

\section{Retrospective Evaluation of Patients with The Diagnosis of Telogen Effluvium}

\author{
Dursun CAAIRCI ${ }^{1}(\mathbb{D})$, Nuray KIVANÇ TERZi ${ }^{1}{ }^{(\mathbb{D})}$, Ezgi DENIZLi ${ }^{1}(\mathbb{D})$ \\ Elif İpek KAPTAN 1 (D), Hasan KARATAŞ $1 \mathbb{1}$, Şenay KOÇAKOĞLU1 $1 \mathbb{D}$
}

1 Harran Üniversitesi Tıp Fakültesi, Aile Hekimliği Anabilim Dalı, Şanlıurfa, Türkiye

Öz.

Amaç: Saç dökülmesi etiyolojisinde, genetik faktörlerin yanı sıra, vitamin eksiklikleri, hormonal ve çevresel nedenler yer alır. Literatürde kadınlarda en sık saç dökülmesi nedeninin telogen effluvium (TE) olduğu bildirilmektedir. Bu araştırmadaki amacımız; hematolojik ve biyokimyasal parametrelerin TE etiyolojisindeki olası ilişkisini araştırmaktır.

Materyal ve metod: Bu çalışma, Harran Üniversitesi Tıp Fakültesi Dermatoloji Polikliniği'ne Temmuz - Aralık 2019 tarihleri arasında yaygın saç kaybı şikâyeti ile başvuran hastaların geriye dönük taranması ile gerçekleştirilmiştir. TE tanısı alan 213 hasta çalışmaya dahil edilmiştir. Hastalara ait laboratuvar tetkiklerinden, serum demiri, demir bağlama kapasitesi, ferritin, folik asit, vitamin B12, tiroid uyarıcı hormon (TSH), serbest T4, hemoglobin $(\mathrm{Hb})$ gibi parametrelerin TE ile ilişkisi incelenmiştir.

Bulgular: TE tanısıyla çalışmaya alınan hastaların çoğunluğunu kadınlar oluşturmaktaydı (\%92). Hastaların \%54'ünde ferritin, $\% 42$ 'sinde demir ve $\% 1$ 'inde B12 eksikliği mevcuttu. Anemi görülme oranı $\% 16$ idi ve aneminin en sık sebebi demir eksikliğiydi. Hastaların \%4'ünde TSH yüksekliği, \%1'inde ise T4 düşüklüğü saptandı. Hastaların hiçbirinde düşük folat düzeyi saptanmazken, \%5'inde yüksek olduğu tespit edildi.

Sonuç: Yaygın saç kaybı şikâyeti ile başvuran hastalarda demir eksikliği anemisinin araştıııması, tiroid fonksiyon testlerinin ve vitamin değerlerinin kontrolü önemlidir. Bu çalışma, saç dökülmesi ile serum demiri ve ferritin düşüklüğünün ilişkili olabileceğini göstermektedir. Demir eksikliğinin düzeltilmesinin saç dökülmesini durdurduğu yönündeki veriler yetersiz olmakla beraber, uygun tedavi hastanın kliniğine göre hekimi tarafından belirlenmelidir. Çalışmamızın, saç dökülmesi şikâyeti ile başvuran hastalarda tanı ve tedavi aşamasında laboratuvar testlerinin rutin olarak kullanılması gerekliliğine dikkat çekmesi açısından önemli olduğunu düşünmekteyiz.

Anahtar Kelimeler: Diffüz alopesi, Etiyoloji, Saç kaybı, Telogen effluvium

\section{Abstract}

Background: Besides genetic factors, vitamin deficiencies, hormonal and environmental causes are included in hair loss etiology. In the literature, telogen effluvium (TE) is reported to be the most common cause of hair loss in women. Our aim in this research; to investigate possible relationships of hematological and biochemical parameters in TE etiology.

Materials and Methods: This study was carried out by retrospective screening of patients who applied to Harran University Faculty of Medicine Dermatology Outpatient Clinic between July and December 2019 with the complaint of diffuse hair loss. A total of 213 patients diagnosed with TE were included in the study. From the laboratory tests of the patients, the relationship of serum iron, iron binding capacity, ferritin, folic acid, vitamin B12, thyroid stimulating hormone $(\mathrm{TSH})$, free T4 and hemoglobin $(\mathrm{Hb})$ with TE have been investigated.

Results: The majority of patients included in the study with the diagnosis of TE were women (92\%). $54 \%$ of patients had ferritin deficiency, $42 \%$ of had iron deficiency and $1 \%$ of had B12 deficiency. The rate of anemia was $16 \%$, and the most common cause of anemia was iron deficiency. TSH elevation was found in $4 \%$ of the patients and low T4 in 1\%. While low folate level was not found in any of the patients, it was detected high in $5 \%$ of the patients.

Conclusion: Investigation of iron deficiency anemia, control of thyroid function tests and vitamin values are important in patients presenting with diffuse hair loss. This study shows that hair loss may be associated with low serum iron and ferritin. Although the data that the correction of iron deficiency stops hair loss is insufficient, proper treatment should be determined by the physician according to the patient's clinic. We think that this study is important in terms of drawing attention to the necessity of routine use of laboratory tests in the diagnosis and treatment stages of patients who apply with hair loss.

Key words: Diffuse alopecia, Etiology, Hair loss, Telogen effluvium

\section{Sorumlu Yazar I \\ Corresponding Author}

\section{Dr. Dursun ÇADIRCI}

Harran Üniversitesi Tıp Fakültesi, Aile Hekimliği Anabilim Dalı, Şanlıurfa, Türkiye

Tel: 04143444004 - 04143444000 Tel: 05054850090

e mail:drdcadirci@harran.edu.tr

Geliş tarihi / Received:

19.11.2020

Kabul tarihi / Accepted: 09.12.2020

DOI: 10.35440/hutfd.827111 


\section{Giriş}

Saç dökülmesi etiyolojisi, önlenemeyen genetik faktörlerin yanı sıra, hormonal nedenler, vitamin eksiklikleri ve çevresel nedenlerden oluşur. Saç kaybı, her geçen gün daha da artan önemli bir kozmetik sorun olarak görülmekte ve hastaların bu nedenle kliniklere başvurma sayıları artmaktadır $(1,2)$. Bu sorunun çözümü olarak da birçok ruhsatı/ruhsatsIz saç ekim merkezleri, alternatif tıp merkezleri bulunmakta ve bunlar hastalara önemli ekonomik külfetler oluşturmaktadır.

Çalışmalar kadınlarda görülen en sık saç dökülmesi nedeninin telogen effluvium (TE) olduğunu göstermiş̧tir. Yine bu çalışmalar, saç kaybına en sık neden olan faktörleri ferritin düşüklüğü, B12 vitamini eksikliği ve tiroid fonksiyon bozuklukları olarak sıralamışlardır $(3,4)$.

Dünyada en sık görülen besinsel eksiklik, demir eksikliğidir (5). Demir eksikliğinin vücutta meydana getirdiği birçok problemden bir tanesi de saç dökülmesidir (3). Hatta bu hastalığın etiyolojisinde en çok suçlanan faktörlerden biri olarak değerlendirilebilir $(6,7)$. Hipertiroidide $\% 55$ 'lere, hipotiroidide ise \%33'lere varan oranlarda saç dökülmesi şikâyeti görülebilmektedir (8-10). B12 vitamini nükleik asit sentezine katılmakta ve eksikliğinde pernisiyöz anemi oluşmaktadır. TE ile B12 vitamini arasındaki ilişki kesin olarak gösterilememekle birlikte, eksikliğinde saçta beyazlama ve dökülme olabileceği ile ilgili çalışmalar mevcuttur $(8,11)$.

Bu araştırmadaki amacımız; ilgili olabileceğini düşündüğümüz laboratuvar ve hematolojik tetkiklerin (Hemoglobin $[\mathrm{Hb}]$, Ferritin, Folik Asit, Vitamin B12, Tiroid Uyarıcı Hormon [TSH], Serbest T4) TE etiyolojisindeki rolünü araştırmaktır.

\section{Materyal ve Metod}

Çalışmamız, Harran Üniversitesi Tıp Fakültesi Dermatoloji Polikliniği'ne Temmuz-Aralık 2019 tarihleri arasında yaygın saç kaybı şikâyeti ile başvuran hastaların geriye dönük taranması ile gerçekleştirilmiştir. Retrospektif olarak planlanan bu araştırmaya kurum izni ve Harran Üniversitesi Tıp Fakültesi Girişimsel Olmayan Klinik Araştırmalar Etik Kurulu'nun 10.02.2020 tarih, 03 nolu oturum ve HRÜ/20.03.02 sayılı onayı sonrasında başlandı. Çalışmamıza, cinsiyet ayırt etmeksizin, bilinen sistemik bir rahatsızlığı olmayan, belli bölgede saç kaybı, skar ya da atrofisi bulunmayan, saç dökülmesine yol açabileceği düşünülen herhangi bir ilaç kullanma öyküsü olmayan hastalar dahil edilmiştir. Alopesi areata ve androgenik alopesi varlığı olan hastalar çalışmadan dışlanmıştır. Anamnezde kadın hastalarda gebelik, düzensiz menstruel döngü ve oral kontraseptif kullanımı belirtilmiş olanlar da çalışmaya kabul edilmemişlerdir. Bu bilgiler ışığında 213 hasta çalışmaya dahil edilmiş ve ilişkili olabileceği düşünülen laboratuvar ve hematolojik tetkiklerden serum demir $(n=204)$, demir bağlama kapasitesi $(n=202)$, ferritin ( $n=202)$, folik asit $(n=179)$, vitamin B 12 ( $n=181), T S H(n=205)$, serbest T4 ( $n=81), H b$ $(n=208)$ değerleri incelenmiş̧ir.

Kayıtlar taranarak elde edilen veriler SPSS 20.0 (Statistical Package for Social Sciences) paket programı ile sayı ve yüzdelik testi kullanılarak değerlendirilmiştir.

\section{Bulgular}

Çalışmamıza dahil edilen hastaların büyük bir çoğunluğunu kadınlar oluşturmaktaydı (\%92). Yaşları 10-67 arasında değişen hastalardan \%25'i $(n=53)$ 10-19, \%47'si ( $n=100)$ 20-29, \%20'si $(n=43) 30-39, \% 5^{\prime} i(n=11)$ 40-49, $\% 2$ 'si $(n=5)$ 50-59 ve \%1'inden azı $(n=1) 60-69$ yaş grubuna dahildi.

Yapılan biyokimyasal ve hematolojik incelemeler sonucunda saptanan değerler, Tablo 1'de gösterilmektedir. Hastaların \%54'ünde ferritin (ferritin değerleri <18 ng/dl), $\% 42$ 'sinde demir (hasta demir değerleri $<60 \mathrm{ug} / \mathrm{dl}$ ) ve $\% 1$ 'inde B12 (B12 değerleri <160 pg/ml) eksikliğine rastlandı. Ek olarak, \%16 oranında saptanan aneminin $(\mathrm{Hb}$ değerleri <12g/dl) sebebi olarak, demir eksikliği gösterildi. Tiroid fonksiyonları değerlendirildiğinde ise hastaların $\% 4$ 'ünde TSH yüksekliği (TSH değerleri $>4.94 \mathrm{ulu} / \mathrm{ml}$ ), \%1'inde de T4 düşüklüğü (T4 değerleri <0.89 ng/dl) saptandı. Hiçbir hastada folat düşüklüğüne (folat değerleri $<3.0 \mathrm{ng} / \mathrm{ml}$ ) rastlanmazken $\% 5$ hastada folat miktarı referans aralığının üzerinde (folat değerleri >17 ng/ml) seyretmekte idi.

Tablo 1. TE hastaların laboratuvar testlerinin referans araliğına göre dağılımları (1).

\begin{tabular}{|c|c|c|c|c|}
\hline Değişken & (n) & Referans aralığı & $\begin{array}{l}\text { Normalin } \\
\text { altı } \\
\mathrm{n}(\%)\end{array}$ & $\begin{array}{l}\text { Normalin } \\
\text { üstü } \\
\mathrm{n}(\%)\end{array}$ \\
\hline Hemoglobin & 208 & $12-16 \mathrm{~g} / \mathrm{dl}$ & $33 \quad(15,9)$ & $9(4,3)$ \\
\hline Demir & 204 & $60-180$ ug/dl & $85 \quad(41,7)$ & $0(0,0)$ \\
\hline Ferritin & 202 & $18-370 \mathrm{ng} / \mathrm{dl}$ & $109(54,0)$ & $0(0,0)$ \\
\hline B12 & 181 & $160-900 \mathrm{pg} / \mathrm{ml}$ & $2 \quad(1,1)$ & $1(0,6)$ \\
\hline TSH & 205 & $0.35-4.94$ ulu/ml & $(1,5)$ & $9(4,4)$ \\
\hline T4 & 81 & $0.89-1.76 \mathrm{ng} / \mathrm{dl}$ & $(1,2)$ & $1(1,2)$ \\
\hline Folik asit & 179 & $3.0-17 \mathrm{ng} / \mathrm{ml}$ & $(0,0)$ & $9(5,0)$ \\
\hline
\end{tabular}

*Değişkenlerin referans aralığı 1 numaralı kaynaktan alınmıştır. TSH: Tiroid Uyarıcı Hormon

\section{Tartışma}

Saç, her ne kadar insanın hayati fonksiyonlarından biri olmasa da eksikliği her iki cinsiyet için de gerek psikolojik gerekse sosyal açıdan önemli bir sorundur. Kozmetik açıdan sıkıntı içeren bir durum olmasından dolayı maalesef $\mathrm{ki}$ umut tacirlerinin çok kullandığı bir durum olabilmektedir. Daha önceki yıllarda bağımsız, tek bir tanı olarak kabul edilen yaygın saç kaybının asında kronik telogen effluvium, psikojenik psödo effluvium ve androgenetik alopesi gibi tiplerinin olduğu ortaya çıkmışır (12).

Bunlar arasında TE, en sık görülen diffüz saç dökülmesi tipidir (12). Hastalık çoğunlukla subklinik seyrettiğinden gerçek insidans net olarak bilinememektedir (13). TE, akut 
ve kronik olarak seyredebilmekte ve kadınları daha sık etkilemektedir (1). Kıl siklusundaki bozukluğa bağlı olarak gelişir. Etiyolojisi idiopatik olabileceği gibi, zemininde endokrinolojik sorunlar, beslenme bozuklukları, psikolojik nedenler veya fiziksel stres gibi birçok sebep de barındırabilir $(3,4,14,15)$. Bu nedenledir ki saç dökülmesi şikâyeti ile gelen hastalarda doğru tanı ve erken tedavi için detaylı hikâye, fizik muayene, laboratuvar tetkiklerini içine alacak şekilde bir sistematik yaklaşım benimsenmelidir $(14,16$, 17).

TE'li hasta grubunun kontrol grubu ile karşılaştırıldığı çalışmalarda laboratuvar değerleri açısından ciddi farklııkların olduğu bulunmuştur ki bu farklılıkların başında demir eksikliği gelmektedir (18). Demir eksikliği hücre çoğalmasını azaltır (19). Bu kişilerde telogen evrenin sonundaki kıl foliküllerinin tekrar anagene girerken geçici olarak başarısız olabilmesi sonucunda TE gelişebilir $(9,10)$.

Moeinvaziri ve ark. yaptıkları çalışmada doğurganlık çağındaki yaygın saç kaybı şikayeti ile gelen hastaları kontrol grubu ile kıyasladıklarında semptom gösteren grubun ortalama ferritin düzeyi kontrol grubuna göre daha düşük bulunmuştur (20). Deloche ve ark. ise henüz menopoza girmemiş 35-60 yaş arası kadın hastaları, hiç şikâyeti olmayan, orta derecede ve şiddetli saç dökülmesi şikâyeti olanlar şeklinde 3 gruba ayırmışlardır. Şiddetli saç dökülmesi şikayeti ile başvuran hastaların \%59'unun serum ferritin düzeyinin $40 \mathrm{ng} / \mathrm{ml}$ 'nin altında bulduklarını bildirmişlerdir (21). Bregy ve Trueb, TE'li hastaların ortalama ferritin düzeyini saptamak istedikleri çalışmalarında sonucu 55,30 $\mathrm{ng} / \mathrm{ml}$ olarak bulmuşlardır. Hastaların yaş ile ferritin düzeyleri arasındaki ilişkiyi incelenmiş ve mensturasyona bağlı olduğunu öne sürerek, gençlerde ferritin düzeylerinin anlamlı olarak düşük saptadıklarını bildirmişlerdir (8). Trost ve ark. saç dökülmesi olan hastalarda demir depolarını incelemiş ve sonucunda, ferritin düzeyi $70 \mathrm{ng} / \mathrm{ml}$ nin altındaki olgulara, anemi olmasa dahi, tedavi verilmesi gerektiğini öne sürmüşlerdir (6).

Avcı ve ark. 563 kadın hasta üzerinde çalışmış ve demir eksikliğinde kıl folliküllerine yeterli oksijen gitmediğini savunmuştur. Çalışmanın sonucunda ise hastaların 77 'sinde (\%13.68) demir düşüklüğü, 174'ünde (\%30.91) ferritin düşüklüğü saptanmıştır (22). Ülkemizde yapılan çalışmalar da paralel sonuçlar görülmektedir. Örneğin 2008 yılında yapılan bir çalışmada ferritin düşüklüğü saptanma oranı \%36 olarak bulunmuştur (1). Yaptığımız çalışma da benzer sonuçlar içermektedir. Kliniğe, son 6 ay içerisinde saç dökülmesi ile başvuran hastalar incelendiğinde hastaların çoğunun kadın olduğu (\%92) görülmektedir. Cinsiyet ayırt etmediğimiz çalışmada hastaların $\% 16$ 'sinda demir eksikliği anemisi, \%54'unde ferritin eksikliği, \%41' inde demir düşüklüğü saptanmıştır.

Nükleik asitlerin yapımında ve bazı amino asitlerin birbirine dönüşümünde görev alan folik asit, saç dökülmesinde suçlanan bir diğer faktördür (23). Özden ve ark. nin 100 kadın hastayı incelediği çalışmalarında sadece 1 hastada folat eksikliği saptamış, 3 hastada ise normalin üstünde bir değer ile karşılaşmışlardır (1). Öztürk ve ark. da çalışmalarında $\% 3$ hastada folat eksikliği, $\% 5$ hastada ise folat fazlalığı tespit etmişlerdir (24). Avcı ve ark. yine laboratuvar sonuçlarındaki anormallikleri değerlendirmek amacı ile yaptıkları çalışmalarında saç dökülmesi ile başvuran hastaların \%9' unda folat eksikliği tespit etmişlerdir (22). Ülkemizde 2016 yılında yapılan başka bir çalışma ise seçilen 108 hastanın hiçbirinde folik asit düzeyi düşük bulunmamıştır. Yine aynı çalışmada ailedeki saç dökülme öyküsü sorgulanmış, şikayet bildirmeyen aileye sahip olan hastaIarın folik asit düzeyi anlamlı oranda daha fazla bulunmuştur (23). Bizim çalışmamızda 179 hastanın folat düzeyine bakılmış ve benzer şekilde hiçbir hastada düşüklük saptanmamıştır. Hastaların \% de 5 "inde ise folik asit yüksekliği saptanmıştır.

TE etiyoloji araştırmalarında değerlendirilen bir diğer kan parametresi de B12 vitaminidir. Eksikliğinde, özellikle alyuvarların gelişimi ve olgunlaşmasının sekteye uğrayabileceği, hem saç dökülmesine hem de beyazlamasına neden olabileceği bilinmektedir $(8,11)$. B12 ve TE ilişkisini inceleyen çalışmalarda sonuçların farklılık arz ettiği söylenebilir. Ülkemizde yapılan çalışmada olguların \%3 ünde B12 vitamin eksikliği tespit edilmiş ve hastalık ile B12 vitamini arasında doğrudan ilişki kurulamayacağı savunulurken, bir başka çalışmada hastaların \%21'inde eksiklik bulunduğuna dikkat çekilmiştir $(22,24)$. Bizim yaptığımız çalışmada olguların sadece $\% 1$ ' inde B12 eksikliği tespit edilmiştir.

Saç dökülmesinde hormonal değişikliklerin yeri 1984 ylInda Mortimer ve arkadaşları tarafından yapılan çalışmada ortaya konmuştur (25). Sonrasında ise saç dökülmesi şikayetleri ile başvuran hastalarda sık çalışılan parametrelerden biri halini almıştır. Hipotiroidizmli hastalarda derinin bazı katmanlarında hücre bölünmesinin durması ve anagen/telogen oranının azalması söz konusudur ve bu durum ise saç kaybına neden olabilmektedir (23). Lo Sicco ve ark.'nın 367 alopesi hastasını geriye dönük incelediklerinde, olguların 8'inde Tiroid fonksiyonları açısından anormallik saptamışlardır ve alopesi hastalarında sadece kan testi çalışmanın yeterli olmadığını, tiroid muayenesi ve ultrasonografisi ile de araştırmanın derinleştirilmesi gerektiğini vurgulamışlardır (26). Avcı ve ark. TE'li 563 kadın hastayı değerlendirdikleri çalışmada tiroid fonksiyon testlerinden en az birinin bozuk olduğu 8 kadın tespit edilmiş ve bu anormalliklerin TE için bir etiyolojik sebep olabileceğini vurgulamışlardır (22). Ülkemizde, altı aydan daha uzun süre yaygın saç dökülmesi şikayeti bulunan hastalıkları inceleyen bir çalışmada hastaların \%18'inde Tiroid fonksiyon bozukluğu olduğunu tespit etmişlerdir (1). Yine ülkemizde yapılan bir başka çalışmada TE'li hastalarda Tiroid fonksiyon testlerine ek olarak Tiroid oto antikorlarının da araştıııma- 
sındaki gerekliliğin üzerinde durulmuştur (27). Bizim çalışmamızda 205 hastanın TSH değerine bakılmış \%2'sinde düşüklük, \%4'ünde yükseklik saptanmıştır. Yine çalışmamızda \%1 hastada T4 düşüklüğü, \%1 hastada T4 yüksekliği saptanmıştır.

Yaygın saç kaybı ile gelen hastalarda istenecek tetkikler açısından ortak bir görüşe varılamamış olmakla birlikte demir eksikliği anemisinin araştıııması, ferritin, tiroid fonksiyon testleri, vitamin değerlerinin kontrolü önemli kabul edilmiştir (6). Demir eksikliği mevcut olan hastalara destek tedavi verilmesinin saç dökülmesini durdurduğu yönündeki veriler yetersiz olmakla birlikte tedavi hastanın kliniğine göre hekimin vereceği karar doğrultusunda olmalıdır (23). Çalışmamız telogen effluvium etyolojisinde serum demir ve ferritin düşüklüğünün etkili olabileceğini düşündürmektedir.

\section{Sonuç}

Saç dökülmesi birey açısından önemli bir psikolojik ve sosyal sorun olarak algılanabilmektedir. Bu çalışmamızın saç dökülmesi ile gelen hastalarda laboratuvar testlerinin rutin olarak istenmesi gerektiğine dikkat çekmesi bakımından önemli olduğunu düşünmekteyiz. Birinci basamakta karşılaşılabilecek sorunlardan biri olan TE hakkında hekimlerin farkındalıklarının olması ve bu konuda yapılacak çalışmaların artması hastalı̆ı̆ın tespiti ve erken tedavi şansını hastalara sunmak adına önemli olacaktır.

\section{Hibe Desteği ve Finansal Destek: Yok.}

Etik onam: Çalışmanın için Harran Üniversitesi Tıp Fakültesi Girişimsel Olmayan Klinik Araştırmalar Etik Kurulu'ndan 10.02.2020 tarih, 03 nolu oturum ve HRÜ/20.03.02 sayılı kararı ile etik onam alınmıştır.

\section{Kaynaklar}

1. Özden MG, Öztaş MO, Gülekon A, Gürer MA. Kadın olgularda yaygın saç kaybı ve eşlik eden bulgular. J Exp Clin Med. 2008;25(2):50-6.

2. Obaidat NA, Rawashdeh BT, Wreikat A, Awamleh AA. A potential relation between telogen effluvium and iron deficiency in adult females. J Res Med Sci. 2005;12(1):62-6.

3. Sinclair R. Diffuse hair loss. Int J Dermatol. 1999;38(S1):8-18.

4. Shrivastava SB. Diffuse hair loss in an adult female: approach to diagnosis and management. Indian $\mathrm{J}$ Dermatol Venereol Leprol. 2009;75(1):20-7.

5. Akyurek FT, Demirbas GU, Demirbas A, Akyurek F, Kurtipek GS. Retrospective evaluation of laboratory data of patients with telogen effluvium. Ann Med Res. 2019;26(12):2754-7.

6. Trost LB, Bergfeld WF, Calogeras $E$. The diagnosis and treatment of iron deficiency and its potential relationship to hair loss. J Am Acad Dermatol. 2006;54(5):824-44.

7. Rushton D, Ramsay I, James K, Norris M, Gilkes J. Biochemical and trichological characterization of diffuse alopecia in women. $\mathrm{Br} \mathrm{J}$ Dermatol. 1990;123(2):187-97.

8. Bregy A, Trüeb RM. No association between serum ferritin levels $>10$ $\mu \mathrm{g} / \mathrm{l}$ and hair loss activity in women. Dermatology. 2008;217(1):1-6.

9. Sperling L. Androgenetic alopecia. An Atlas of Hair Pathology with Clinical Correlations 1st ed New York, NY: The Parthenon Publishing Group. 2003:37-42.

10. Rushton D. Nutritional factors and hair loss. Clin Exp Dermatol. 2002;27(5):396-404.
11. Niiyama S, Mukai H. Reversible cutaneous hyperpigmentation and nails with white hair due to vitamin B 12 deficiency. Eur J Dermatol. 2007;17(6):551-2.

12. Özdemir Ş. Kadınlarda Kronik İdyopatik Telogen Effluvium. Turkiye Klinikleri J Int Med Sci. 2005;1(48):99-102.

13. Springer K, Brown M, Stulberg DL. Common hair loss disorders. Am Fam Physician. 2003;68(1):93-102.

14. Serdaroğlu, S.; Oğuz, O. Saç hastalıkları. Tüzün Y, Gürer MA, Serdaroğlu S, Oğuz O, Aksungur VL (Editörler). Dermatoloji'de, 2008, 3: 1295-344.

15. Odom RB, James WD, Berger TG. Andrew's Disease of the Skin Clinical Dermatology. 9th ed. Philadelphia: WB Saunder's Company. 2000; 946-7.

16. Han A, Mirmirani $P$, editors. Clinical approach to the patient with alopecia. Semin Cutan Med Surg 2006; 25(1): 11-23.

17. Chamberlain AJ, Dawber RP. Methods of evaluating hair growth. Australas J Dermatol. 2003;44(1):10-8.

18. Thelander $L$, Reichard $P$. Reduction of ribonucleotides. Annu Rev Biochem. 1979;48(1):133-58.

19. Alotaibi MK. Telogen effluvium: a review. ijmdc. 2019;3(10):797801.

20. Moeinvaziri M, Mansoori P, Holakooee K, Safaee Naraghi Z, Abbasi A. Iron status in diffuse telogen hair loss among women. Acta Dermatovenerol Croat. 2009;17(4): 279- 84.

21. Deloche $C$, Bastien $P$, Chadoutaud $S$, Galan $P$, Bertrais $S$, Hercberg $\mathrm{S}$, de Lacharrière $\mathrm{O}$. Low iron stores: a risk factor for excessive hair loss in nonmenopausal women. Eur J Dermatol 2007; 17(6): 507-12.

22. Avcı A, Avcı D, Özyurt K. Telogen effluviumlu 563 kadın hastada laboratuvar bulguları. Med J Bakirkoy.. 2015;11:120-3.

23. Bilik L. Diffüz Saç Dökülmesi Olan Hastalarda Digital Fototrikogram Bulgularının Kandaki TSH, Ferritin ve B12 Vitamin Düzeyi ile Illişkisinin Değerlendirilmesi T.C. Fırat Üniversitesi Tıp Fakültesi, Uzmanlık Tezi. 2016.

24. Öztürk $P$, Ataseven A, Kurutaş E. Menopoz Dönemi Dışındaki Kadınlardaki Telogen Alopeside Serum Ferritin, Vit B12 ve Folat Düzeyleri. Turk J Dermatol. 2012;6:117-8.

25. Mortimer $\mathrm{CH}$, Rushton $\mathrm{H}$, James KC. Effective medical treatment for common baldness in women. Clin Exp Dermatol. 1984;9(4):342-50.

26. Lo Sicco K, McGuire S, English JC. A retrospective study of thyroid structural abnormalities in alopecia patients. Dermatoendocrinol. 2011;3(4):251-4.

27. Güngör S, Topal I, Gökdemir G. Telogen Effluviumlu Kadin Hastalarda Tiroid Otoimmünitesinin Degerlendirilmesi/Evaluation of Thyroid Autoimmunity in Female Patients with Telogen Effluvium. Turkiye Klinikleri J Med Sci. 2014;34(1):93-6. 